\title{
Oxygen ionic conduction in brownmillerite $\mathrm{CaAl}_{0.5} \mathrm{Fe}_{0.5} \mathrm{O}_{2.5+\delta}$
}

\author{
V.V. Kharton ${ }^{\text {a,b,* }}$, I.P. Marozau ${ }^{\mathrm{b}}$, N.P. Vyshatko ${ }^{\mathrm{a}}$, A.L. Shaula ${ }^{\mathrm{a}}$, A.P. Viskup ${ }^{\mathrm{b}}$, \\ E.N. Naumovich ${ }^{\mathrm{b}}$, F.M.B. Marques ${ }^{\mathrm{a}}$ \\ ${ }^{a}$ Department of Ceramics and Glass Engineering, CICECO, University of Aveiro, 3810-193 Aveiro, Portugal \\ ${ }^{\mathrm{b}}$ Institute of Physicochemical Problems, Belarus State University, 14 Leningradskaya Str., 220050 Minsk, Belarus
}

Received 19 December 2002; received in revised form 21 February 2003; accepted 28 February 2003

\begin{abstract}
The oxygen permeability of $\mathrm{CaAl}_{0.5} \mathrm{Fe}_{0.5} \mathrm{O}_{2.5+\delta}$ brownmillerite membranes at $1123-1273 \mathrm{~K}$ was found to be limited by the bulk ionic conduction, with an activation energy of $170 \mathrm{~kJ} / \mathrm{mol}$. The ion transference numbers in air are in the range $2 \times 10^{-3}$ to $5 \times 10^{-3}$. The analysis of structural parameters showed that the ionic transport in the $\mathrm{CaAl}_{0.5} \mathrm{Fe}_{0.5} \mathrm{O}_{2.5+\delta}$ lattice is essentially along the $c$ axis. The largest ion-migration channels are found in the perovskite-type layers formed by iron-oxygen octahedra, though diffusion in tetrahedral layers of the brownmillerite structure is also possible. Heating up to $700-800 \mathrm{~K}$ in air leads to losses of hyperstoichiometric oxygen, accompanied with a drastic expansion and, probably, partial disordering of the $\mathrm{CaAl}_{0.5} \mathrm{Fe}_{0.5} \mathrm{O}_{2.5+\delta}$ lattice. The average thermal expansion coefficients of $\mathrm{CaAl}_{0.5} \mathrm{Fe}_{0.5} \mathrm{O}_{2.5+\delta}$ ceramics in air are $16.7 \times 10^{-6}$ and $12.6 \times 10^{-6} \mathrm{~K}^{-1}$ at $370-850$ and $930-1300 \mathrm{~K}$, respectively.
\end{abstract}

(C) 2003 Elsevier Science Ltd. All rights reserved.

Keywords: A. Oxides; D. Ionic conductivity; D. Electrical properties; D. Crystal structure; D. Thermal expansion

\section{Introduction}

Mixed-conducting oxide materials have promising applications in high-temperature electrochemical devices, such as ceramic membranes for oxygen separation and partial oxidation of hydrocarbons, electrodes of solid oxide fuel cells (SOFCs), and sensors [1-5]. A high level of oxygen ionic conductivity is characteristic of perovskite-type ferrites derived from $\mathrm{AFeO}_{3-\delta}$, where $\mathrm{A}$ corresponds to the alkaline earth cations $[1,4-6]$. However, these phases exhibit a number of specific disadvantages, including thermodynamic and/or dimensional instability under high oxygen chemical potential gradients, very high thermal expansion coefficients (TECs), and reactivity with carbon dioxide and water vapor. One promising approach to enhance the materials stability refers to incorporation of stable

\footnotetext{
* Corresponding author. Tel.: +351-234-370263; fax: +351-234-425300.

E-mail address: kharton@cv.ua.pt (V.V. Kharton).
} 


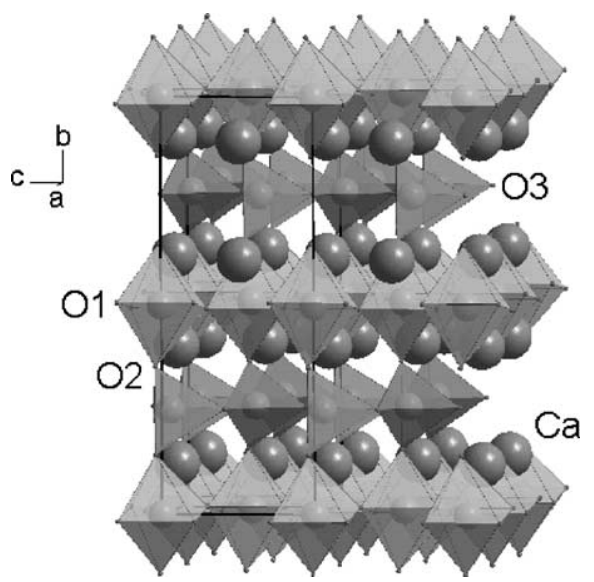

Fig. 1. The brownmillerite structure of $\mathrm{CaAl}_{0.5} \mathrm{Fe}_{0.5} \mathrm{O}_{2.5+\delta}$, drawn using the Rietveld refinement results. Oxygen ions are placed at the corners of $\mathrm{B}-\mathrm{O}$ polyhedra.

trivalent cations, such as $\mathrm{Ga}$ or $\mathrm{Al}$, into the iron sublattice of perovskite-like ferrites [4,7-9]. This type of doping suppresses oxygen non-stoichiometry variations when the oxygen partial pressure or temperature changes; as a result, both thermal and chemically induced lattice expansion decreases $[4,8]$. On the other hand, oxidation state of $\mathrm{Ga}$ or $\mathrm{Al}$ is lower than that of Fe cations in oxidizing conditions; this doping leads, hence, to higher total oxygen non-stoichiometry [10] and may thus increase tendency to form vacancy-ordered brownmillerite-like phases when $\delta$ is close to 0.4-0.5 [4]. Stability of ferrite-based materials in $\mathrm{CO}_{2^{-}}$and $\mathrm{H}_{2} \mathrm{O}$-containing atmospheres may be improved by decreasing the A-site cation radius, e.g. by substitution of $\mathrm{Sr}$ with $\mathrm{Ca}$, which also promotes brownmillerite formation [6].

The structure of brownmillerite, $\mathrm{A}_{2} \mathrm{~B}_{2} \mathrm{O}_{5}$, consists of alternating perovskite layers of corner-sharing $\mathrm{BO}_{6}$ octahedra and layers of $\mathrm{BO}_{4}$ tetrahedra (Fig. 1), and can be considered as an oxygen-deficient perovskite where the oxygen vacancies are ordered along $\left(\begin{array}{lll}0 & 1 & 0\end{array}\right)$ planes [11]. These vacancies were assumed to significantly contribute to ionic transport, forming one-dimensional diffusion pathway for oxygen ion migration in the tetrahedral layers $[12,13]$. On the contrary, experimental data on partially ordered ferrites $[6,11,14]$ suggest that oxygen-vacancy ordering leads to decreasing ionic conduction. Studying of the ionic transport in brownmillerite-type compounds may therefore provide a better understanding of oxygen diffusion processes in ferrite phases. Continuing our research on $\mathrm{Fe}$ containing mixed conductors $[6,8,10,14-16]$, the present work is focused on the determination of ionic conductivity of brownmillerite $\mathrm{CaAl}_{0.5} \mathrm{Fe}_{0.5} \mathrm{O}_{2.5}$ and on the evaluation of structural factors affecting ion mobility in the brownmillerite lattice.

\section{Experimental}

In order to prepare dense $\mathrm{CaAl}_{0.5} \mathrm{Fe}_{0.5} \mathrm{O}_{2.5}$ ceramics with a fine homogeneous microstructure, the glycine-nitrate process (GNP) was used. This synthesis technique, a self-combustion method using glycine as fuel and nitrates of the metal components as oxidant, is well known as appropriate for multicomponent systems, where the use of a standard ceramic route may be hampered due to kinetic 
reasons $[17,18]$. In the course of GNP, the stoichiometric amounts of high-purity $\mathrm{Ca}\left(\mathrm{NO}_{3}\right)_{2}, \mathrm{Al}(\mathrm{OH})_{3}$, and $\mathrm{Fe}\left(\mathrm{C}_{2} \mathrm{O}_{4}\right)_{2} \cdot 2 \mathrm{H}_{2} \mathrm{O}$ were dissolved in an aqueous solution of nitric acid with subsequent addition of glycine (molar glycine/nitrate ratio of 1.5). After drying and firing, the resultant powder having a foamed structure was ball-milled; ceramic samples were pressed at 250-350 MPa and sintered in air at $1553 \pm 10 \mathrm{~K}$ for $5 \mathrm{~h}$. Formation of a single brownmillerite phase was confirmed by X-ray diffraction (XRD) analysis; the cation composition was verified by ion-coupled plasma (ICP) spectroscopy. In order to obtain equilibrium oxygen content after sintering, the ceramics was annealed in air at $1273 \mathrm{~K}$ for $3 \mathrm{~h}$, slowly cooled (cooling rate of 1-2 K/min) and kept at room temperature for 20-25 days. XRD spectra of powders, obtained by grinding the ceramic samples, were collected at room temperature in the $2 \theta$ range from 10 to $100^{\circ}$ (step $0.02^{\circ}, 2 \mathrm{~s} / \mathrm{step}, \mathrm{Cu} \mathrm{K} \alpha$ radiation). Structural parameters were refined using the Fullprof program [19]. Rietveld refinement consisted of 44 parameters, including the scale factor, five-parameter background function, peak-shape coefficient, detector zero-point, profile shape parameter, three lattice constants, three FWHM parameters, four asymmetry parameters, and the coordinates, isotropic temperature factors, and occupation numbers for all atoms in the asymmetric unit cell, except for the occupancy of oxygen sites. Final Rietveld plot is presented in Fig. 2. The density of the ceramic material $\left(\rho_{\text {exp }}\right)$, determined by the standard picnometric technique, was $95.2 \%$ of the theoretical density $\left(\rho_{\text {theor }}\right)$ calculated from XRD data (Table 1). The characterization of $\mathrm{CaAl}_{0.5} \mathrm{Fe}_{0.5} \mathrm{O}_{2.5}$ ceramics included also scanning electron microscopy combined with energy dispersive spectroscopy (SEM/EDS), dilatometry, differential thermal and thermogravimetric analysis (DTA/TGA), and the measurements of total conductivity (four-probe DC) and steady-state oxygen permeability. The experimental procedures and equipment used for the characterization were reported elsewhere ([6,8-10,14-16] and references cited). All data on the oxygen permeation presented in this

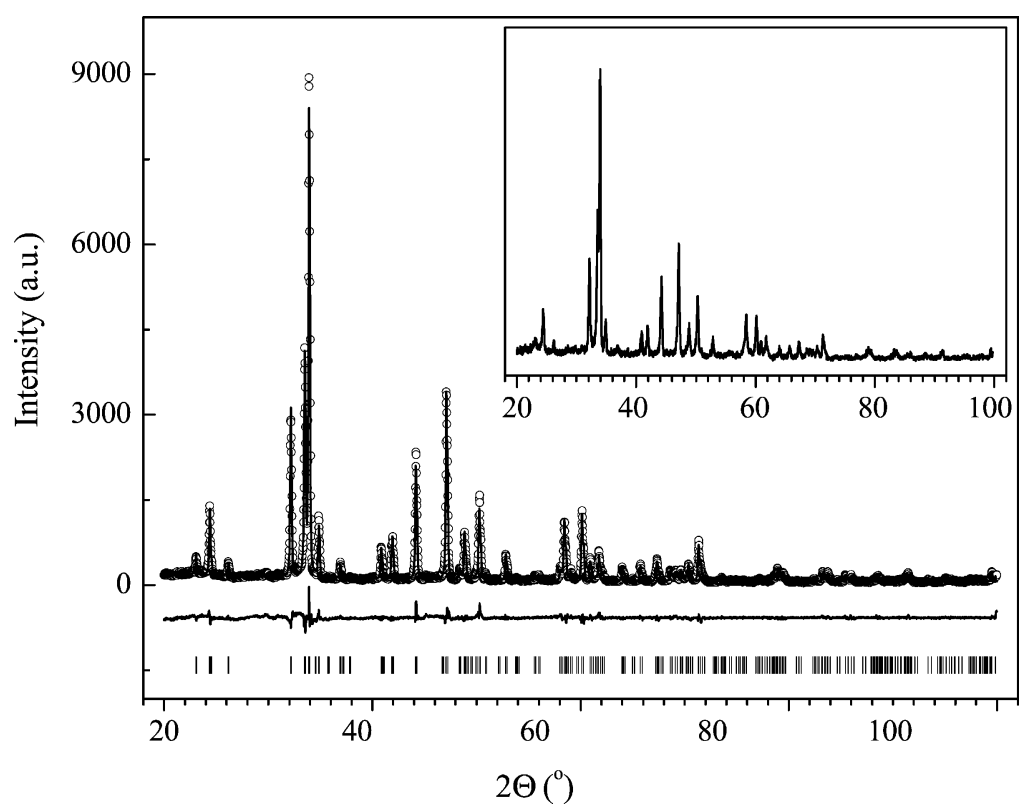

Fig. 2. Observed, calculated, and difference XRD patterns of $\mathrm{CaAl}_{0.5} \mathrm{Fe}_{0.5} \mathrm{O}_{2.5+\delta}$ at room temperature. Inset shows XRD spectrum of the sample, annealed at $1273 \mathrm{~K}$ in air and quenched in liquid nitrogen. 
Table 1

Properties of $\mathrm{CaAl}_{0.5} \mathrm{Fe}_{0.5} \mathrm{O}_{2.5+\delta}$ ceramics

\begin{tabular}{|c|c|c|c|c|c|}
\hline \multirow{2}{*}{$\begin{array}{l}\text { Unit cell } \\
\text { parameters }(\AA)\end{array}$} & \multirow{2}{*}{$\begin{array}{l}\text { Relative density } \\
\left(\rho_{\exp } / \rho_{\text {theor }}\right)(\%)\end{array}$} & \multicolumn{2}{|c|}{ Average TECs } & \multicolumn{2}{|c|}{ Ion transference numbers in air } \\
\hline & & $T(\mathrm{~K})$ & $\alpha \times 10^{6}\left(\mathrm{~K}^{-1}\right)$ & $T(\mathrm{~K})$ & $t_{\mathrm{o}}\left( \pm 0.3 \times 10^{-3}\right)$ \\
\hline $\begin{array}{l}a=5.566(9) \\
b=14.514(9) \\
c=5.349(1)\end{array}$ & $95.2 \pm 0.2$ & $\begin{array}{l}370-850 \\
930-1300\end{array}$ & $\begin{array}{l}16.7 \pm 0.2 \\
12.6 \pm 0.1\end{array}$ & $\begin{array}{l}1248 \\
1223 \\
1173 \\
1123\end{array}$ & $\begin{array}{l}4.3 \times 10^{-3} \\
3.3 \times 10^{-3} \\
2.5 \times 10^{-3} \\
2.0 \times 10^{-3}\end{array}$ \\
\hline
\end{tabular}

paper correspond to the membrane feed-side oxygen partial pressure $\left(p_{2}\right)$ of $21 \mathrm{kPa}$ (atmospheric air); the permeate-side oxygen pressure $\left(p_{1}\right)$ varied from 0.8 to $20 \mathrm{kPa}$.

\section{Results and discussion}

\subsection{General characterization}

The structural refinement of $\mathrm{CaAl}_{0.5} \mathrm{Fe}_{0.5} \mathrm{O}_{2.5}$ at room temperature showed formation of an orthorhombic brownmillerite lattice (space group Ibm2, No. 46), in agreement with the literature [20]. The unit cell parameters (Table 1) are very close to those of the JCPDS data (Card No. 30-0226). Selected refinement results are presented in Table 2. The B-site cations, Al and Fe, are distributed between two non-equivalent B-sites in the brownmillerite structure. The octahedrally coordinated site (B1) is mainly occupied by iron, whereas most aluminum ions are placed in the tetrahedral positions (B2). The ratio of Fe:Al cation concentrations in the B1 sublattice, equal to 80:20, well coincides with data by Colville and Geller [20] who reported this relationship as 76:24.

No traces of liquid phase formation or phase impurities at the grain boundaries of $\mathrm{CaAl}_{0.5} \mathrm{Fe}_{0.5} \mathrm{O}_{2.5+\delta}$ ceramics were detected by SEM/EDS inspection. The average grain size in the studied material was in the range $2-5 \mu \mathrm{m}$; one example of typical SEM micrograph is given in Fig. 3.

Reduction of $\mathrm{CaAl}_{0.5} \mathrm{Fe}_{0.5} \mathrm{O}_{2.5+\delta}$ in hydrogen revealed a presence of hyperstoichiometric oxygen, presumably located in the vacancies ordered in the tetrahedral layers of brownmillerite lattice (Fig. 1);

Table 2

Atomic coordinates in $\mathrm{CaAl}_{0.5} \mathrm{Fe}_{0.5} \mathrm{O}_{2.5+\delta}$ brownmillerite lattice

\begin{tabular}{lllll}
\hline Atom & Occupancy & $x$ & $y$ & $z$ \\
\hline $\mathrm{Ca}$ & $1.00(7)$ & $0.0258(6)$ & $0.1085(6)$ & $0.4916(2)$ \\
$\mathrm{Fe} 1$ & $0.80(8)$ & 0 & 0 & 0 \\
$\mathrm{Fe} 2$ & $0.20(8)$ & $0.9265(8)$ & 0.25 & $0.9584(5)$ \\
$\mathrm{Al1}$ & $0.20(8)$ & $0.9265(8)$ & 0 & 0 \\
$\mathrm{~A} 12$ & $0.80(8)$ & $0.255(0)$ & 0.25 & $0.9584(5)$ \\
$\mathrm{O} 1$ & $1.00(-)$ & $0.069(7)$ & $0.987(8)$ & $0.245(8)$ \\
$\mathrm{O} 2$ & $1.00(-)$ & $0.859(8)$ & $0.144(4)$ & $0.028(1)$ \\
$\mathrm{O} 3$ & $1.00(-)$ & 0.25 & $0.613(1)$ \\
\hline
\end{tabular}

$R_{\mathrm{p}}=8.11 \% ; R_{\mathrm{wp}}=11.1 \% ; \chi^{2}=2.59$. 


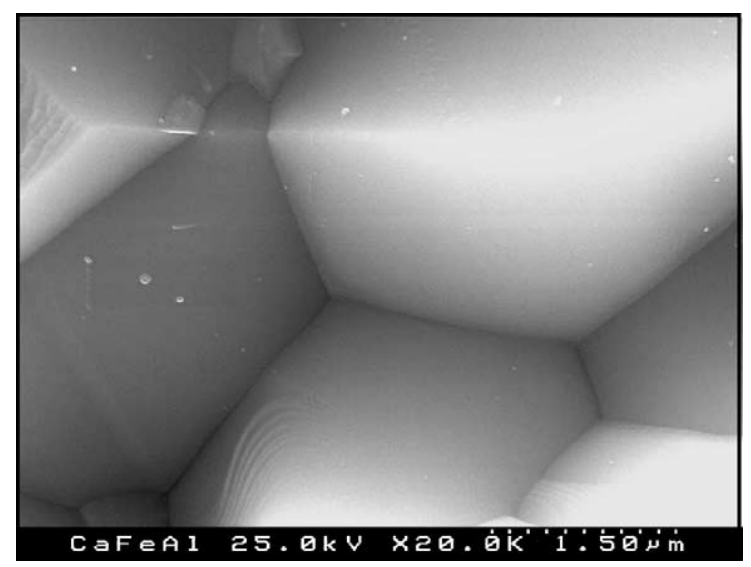

Fig. 3. SEM micrographs of $\mathrm{CaAl}_{0.5} \mathrm{Fe}_{0.5} \mathrm{O}_{2.5+\delta}$ ceramics.

the value of non-stoichiometry $(\delta)$ at room temperature was estimated as $0.06 \pm 0.02$. On heating up at $700-800 \mathrm{~K}$ in air, the extra oxygen starts to leave the lattice (Fig. 4A). This is accompanied by an increase in the activation energy $\left(E_{\mathrm{a}}\right)$ for total conductivity from 56 to $93 \mathrm{~kJ} / \mathrm{mol}$ (Table 3 ), a broad endothermal peak indicated by DTA, and a drastic expansion detected in the dilatometric curves (Fig. 4B). The latter phenomenon is not common in perovskite-type ferrites losing oxygen on heating
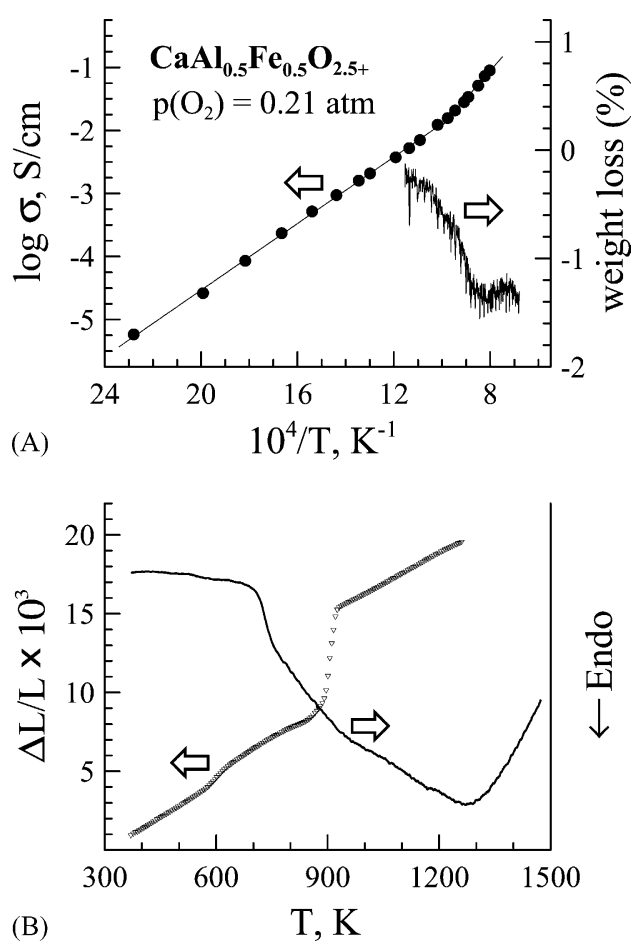

Fig. 4. Total conductivity and TGA curve (A), and the dilatometric and DTA curves (B) of $\mathrm{CaAl}_{0.5} \mathrm{Fe}_{0.5} \mathrm{O}_{2.5+\delta}$ in air. All data obtained on heating (heating rate of $5 \mathrm{~K} / \mathrm{min}$ for thermal analysis and $1-2 \mathrm{~K} / \mathrm{min}$ for total conductivity measurements). 
Table 3

Parameters of the Arrhenius model for the total and ionic conductivities of $\mathrm{CaAl}_{0.5} \mathrm{Fe}_{0.5} \mathrm{O}_{2.5+\delta}$ ceramics in air

\begin{tabular}{|c|c|c|c|c|c|}
\hline \multicolumn{3}{|c|}{ Total conductivity } & \multicolumn{3}{|c|}{ Ionic conductivity } \\
\hline$T(\mathrm{~K})$ & $E_{\mathrm{a}}(\mathrm{kJ} / \mathrm{mol})$ & $\ln \left(A_{0}\right)(\mathrm{S} \mathrm{K} / \mathrm{cm})$ & $T(\mathrm{~K})$ & $E_{\mathrm{a}}(\mathrm{kJ} / \mathrm{mol})$ & $\ln \left(A_{0}\right)(\mathrm{S} \mathrm{K} / \mathrm{cm})$ \\
\hline $400-950$ & $56 \pm 1$ & $9.2 \pm 0.2$ & $1123-1248$ & $170 \pm 9$ & $16 \pm 1$ \\
\hline $1000-1270$ & $93 \pm 5$ & $13.7 \pm 0.6$ & & & \\
\hline
\end{tabular}

$E_{\mathrm{a}}$ and $A_{0}$ are the activation energy and pre-exponential factor of the standard Arrhenius model for conductivity, $\sigma=$ $\left(A_{0} / T\right) \exp \left(-E_{\mathrm{a}} / R T\right)$.

[6,14], being indicative of phase transitions. However, XRD analysis of the samples, equilibrated in air at elevated temperatures and then quenched in liquid nitrogen, demonstrated that at temperatures up to $1300 \mathrm{~K}$ the brownmillerite lattice is kept. An example of XRD pattern of $\mathrm{CaAl}_{0.5} \mathrm{Fe}_{0.5} \mathrm{O}_{2.5 \pm \delta}$ quenched from $1273 \mathrm{~K}$ is shown as inset in Fig. 2. Therefore, the results on oxygen ionic conductivity, presented in this paper, are related to the brownmillerite phase. The effects observed by dilatometry and DTA/ TGA can be attributed to partial disordering in the oxygen and, probably, B-site cation sublattices of $\mathrm{CaAl}_{0.5} \mathrm{Fe}_{0.5} \mathrm{O}_{2.5+\delta}$. In particular, a Frenkel-type disordering, resulting in the formation of oxygen vacancies in the octahedral layers and extra oxygen ions in the tetrahedral layers, might be expected. Note that similar conductivity behavior is typical for many brownmillerite-type compounds, such as $\mathrm{Ba}_{2} \mathrm{In}_{2} \mathrm{O}_{5}$, at temperatures around the "brownmillerite-perovskite" transition when the disordering processes start [21].

\subsection{Oxygen permeability and transference numbers}

Fig. 5A presents the dependence of the oxygen permeation fluxes $(j)$ through $\mathrm{CaAl}_{0.5} \mathrm{Fe}_{0.5} \mathrm{O}_{2.5+\delta}$ ceramics of various thickness on the oxygen partial pressure gradient. The corresponding values of the specific oxygen permeability $J\left(\mathrm{O}_{2}\right)$, shown in Fig. $5 \mathrm{~B}$, were calculated as $[6,8,9]$

$$
j=\frac{J\left(\mathrm{O}_{2}\right)}{d} \ln \left(\frac{p_{2}}{p_{1}}\right)
$$

where $d$ is the membrane thickness. Whilst the permeation fluxes decrease with increasing $d$, the values of $J\left(\mathrm{O}_{2}\right)$ are thickness-independent within the limits of experimental error. This means that the integral form of the Wagner law is observed, unambiguously indicating a negligible effect of the surface exchange kinetics on the overall oxygen transport, which is limited by the bulk ambipolar conductivity. Such a behavior was observed within all studied temperature range, 1123-1273 K. Notice that negligible surface exchange limitations to the oxygen transport in oxidizing atmospheres are characteristic of many ferrite phases with a relatively low ionic conductivity, including $\mathrm{La}(\mathrm{A}) \mathrm{FeO}_{3-\delta}$ $(\mathrm{A}=\mathrm{Pb}, \mathrm{Sr})$ and $\mathrm{Sr}_{4} \mathrm{Fe}_{6} \mathrm{O}_{13 \pm \delta}[15,16]$.

The fact that the permeation fluxes through brownmillerite membranes are predominantly limited by the bulk ambipolar conduction made it possible to calculate the ion transference numbers and ionic conductivity from data on oxygen permeability and total conductivity. The values of the ambipolar conductivity were estimated from the slope of $j$ versus $\ln \left(p_{2} / p_{1}\right)$ dependencies at minimum oxygen pressure gradient, as described elsewhere [6,8,15]. The oxygen ion transference numbers of $\mathrm{CaAl}_{0.5} \mathrm{Fe}_{0.5} \mathrm{O}_{2.5+\delta}$ ceramics vary in the range $2 \times 10^{-3}$ to $5 \times 10^{-3}$ (Table 1 ), suggesting that the 


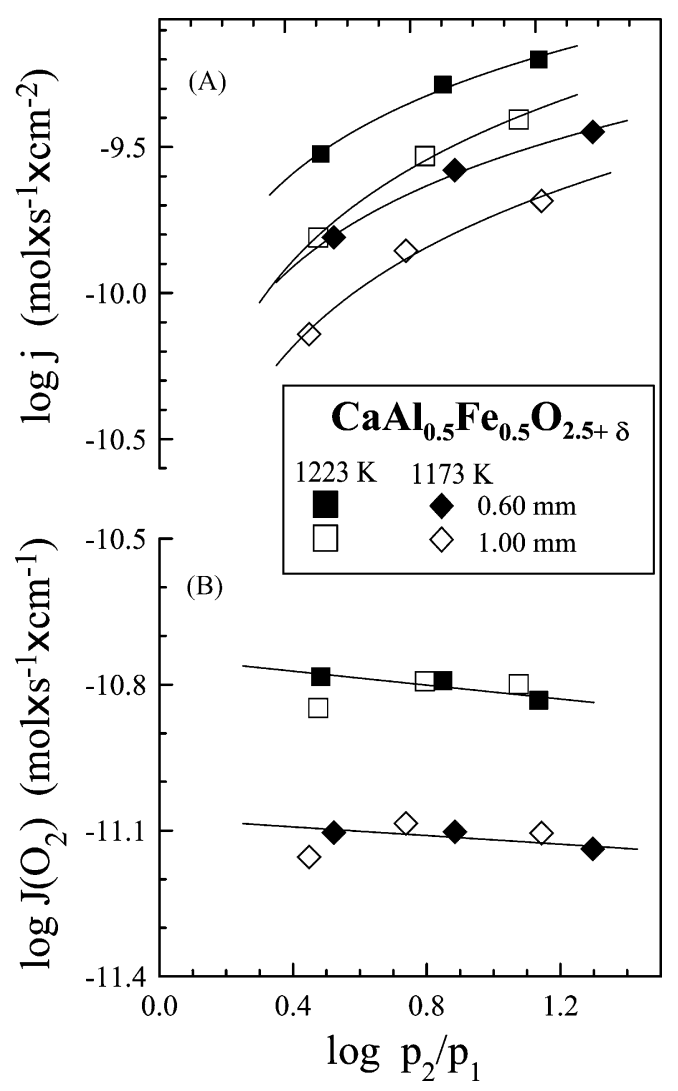

Fig. 5. Oxygen permeation fluxes (A) and specific oxygen permeability (B) of $\mathrm{CaAl}_{0.5} \mathrm{Fe}_{0.5} \mathrm{O}_{2.5+\delta}$ ceramics, as functions of the oxygen partial pressure gradient and membrane thickness.

ambipolar conductivity of this brownmillerite is almost independent of electronic conduction and determined primarily by the ionic transport. As the activation energy for ionic conductivity is higher than that for electronic (Table 3), increasing temperature leads to a greater ionic contribution to the total conductivity.

\subsection{Ionic conductivity}

The oxygen ionic conductivity of $\mathrm{CaAl}_{0.5} \mathrm{Fe}_{0.5} \mathrm{O}_{2.5+\delta}$ is relatively low, comparable to that of other ferrite phases with low concentrations of ionic charge carriers (Fig. 6). Examples of such ferrites may include $\mathrm{Sr}_{4} \mathrm{Fe}_{6} \mathrm{O}_{13+\delta}$ [15], $\mathrm{La}(\mathrm{Pb}) \mathrm{FeO}_{3-\delta}$ [16], and $\mathrm{Y}_{3} \mathrm{Fe}_{5} \mathrm{O}_{12^{-}}$and $\mathrm{Gd}_{3} \mathrm{Fe}_{5} \mathrm{O}_{12}$-based garnets [22]. In fact, the total oxygen content in $\mathrm{CaAl}_{0.5} \mathrm{Fe}_{0.5} \mathrm{O}_{2.5+\delta}$ at elevated temperatures becomes close to stoichiometric (Fig. 4). In these conditions, ionic charge carriers, namely the extra oxygen ions in tetrahedral layers and vacancies in the iron-oxygen octahedra, can be formed only due to partial Frenkel-type disorder. As a particular result, the activation energy for ionic conduction, $170 \mathrm{~kJ} / \mathrm{mol}$ (Table 3), should include not only the ion-migration contribution, but also the energy for the defect formation. Another important factor resulting in the low ionic conductivity of $\mathrm{CaAl}_{0.5} \mathrm{Fe}_{0.5} \mathrm{O}_{2.5+\delta}$ is an 


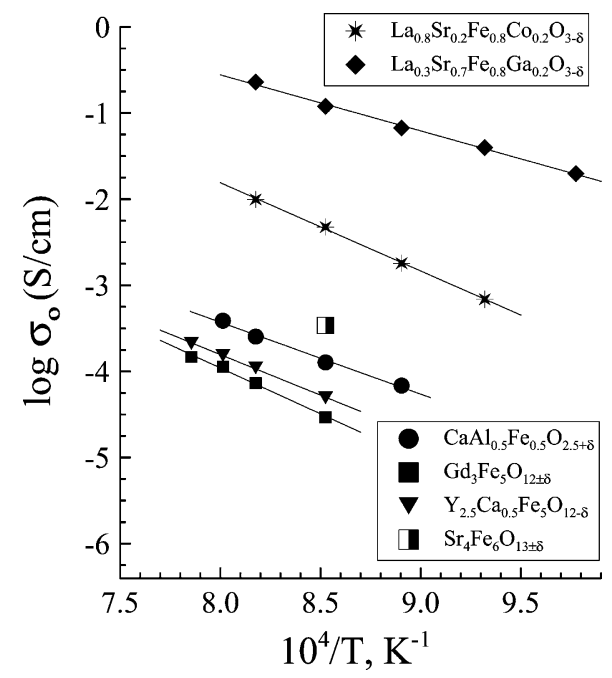

Fig. 6. Temperature dependence of the oxygen ionic conductivity of $\mathrm{CaAl}_{0.5} \mathrm{Fe}_{0.5} \mathrm{O}_{2.5+\delta}$ ceramics in air. Data on other ferritebased materials $[8,15,22]$ are shown for comparison.

essentially one-dimensional character of the ion migration, as revealed by the analysis of structural data.

According to simplified perspectives on the role of stereological features on ionic transport, the diffusion may be affected by a number of structural parameters, such as the specific free volume of the unit cell, tolerance factor, or the size and curvature of channels available for mobile oxygen anions $[1,12,22,23]$. The specific free volume $\left(V_{\mathrm{sf}}\right)$ of $\mathrm{CaAl}_{0.5} \mathrm{Fe}_{0.5} \mathrm{O}_{2.5+\delta}$, estimated as [23]

$$
V_{\mathrm{sf}}=\frac{V-V_{\text {ion }}}{V}
$$

with $V$ and $V_{\text {ion }}$ being the unit cell volume and the total volume of ions constituting one unit cell, respectively, was found to be approximately equal to 0.410. This is smaller than that of $\mathrm{Y}_{2.5} \mathrm{Ca}_{0.5} \mathrm{Fe}_{5} \mathrm{O}_{12-\delta}$, where $V_{\text {sf }} \approx 0.459$, whereas the ionic conductivity of $\mathrm{CaAl}_{0.5} \mathrm{Fe}_{0.5} \mathrm{O}_{2.5+\delta}$ is higher (Fig. 6). Hence, the concept of free volume [12,23], developed for perovskite-type oxides, cannot be applied for comparison of phases with different structural types.

Table 4 lists the ion-migration channel sizes (so-called "bottlenecks") for the $\mathrm{CaAl}_{0.5} \mathrm{Fe}_{0.5} \mathrm{O}_{2.5+\delta}$ lattice, estimated from the Rietveld refinement results (Table 2) by assuming linear diffusion pathways between each two neighboring oxygen sites. These estimations showed that, if the probability of an ion jump in a given direction is proportional to the bottleneck size, ionic transport along the $b$ axis of the brownmillerite structure is unlikely; the highest ion mobility may be expected in the octahedral and tetrahedral layers.

Fig. 7 suggests ion jump probabilities in the directions parallel to $a-c$ planes. The jumps between each pair of oxygen positions are shown by arrows, starting from the corresponding site and with length proportional to the migration channel size. Due to the tilting of B-O polyhedra, the ionic transport is almost one-dimensional, parallel to $c$ axis. The maximum probability could be expected for the ion diffusion in the perovskite layers (Fig. 7, left). The jumps between $\mathrm{O} 2-\mathrm{O} 2$ and $\mathrm{O} 3-\mathrm{O} 3$ pairs are also quite likely, but these bonds form crooked diffusion pathways, which is expected to decrease the total 
Table 4

Comparison of the geometrical parameters of selected oxygen ion jumps in the lattice of $\mathrm{CaAl}_{0.5} \mathrm{Fe}_{0.5} \mathrm{O}_{2.5+\delta}$

\begin{tabular}{lll}
\hline Jump & Jump distance $(\AA)$ & $\begin{array}{l}\text { Minimum radius of ion-migration channel } \\
\text { formed by surrounding cations }(\AA)\end{array}$ \\
\hline O1-O1 & $0.531(3)$ \\
O1-O1 & $0.531(8)$ \\
O1-O1 & $2.750(8)$ & $1.166(9) \times 2$ \\
$\mathrm{O} 1-\mathrm{O} 2$ & $2.860(8)$ & $0.199(0)$ \\
$\mathrm{O} 1-\mathrm{O} 2$ & $2.675(1) \times 2$ & $0.241(3)$ \\
$\mathrm{O} 1-\mathrm{O} 2$ & $3.005(0)$ & $0.179(4)$ \\
$\mathrm{O} 1-\mathrm{O} 2$ & $2.881(9)$ & $0.250(5)$ \\
$\mathrm{O} 2-\mathrm{O} 3$ & $2.754(1)$ & $0.607(2)$ \\
$\mathrm{O} 3-\mathrm{O} 3$ & $2.897(5)$ & $1.014(2)$ \\
\hline
\end{tabular}
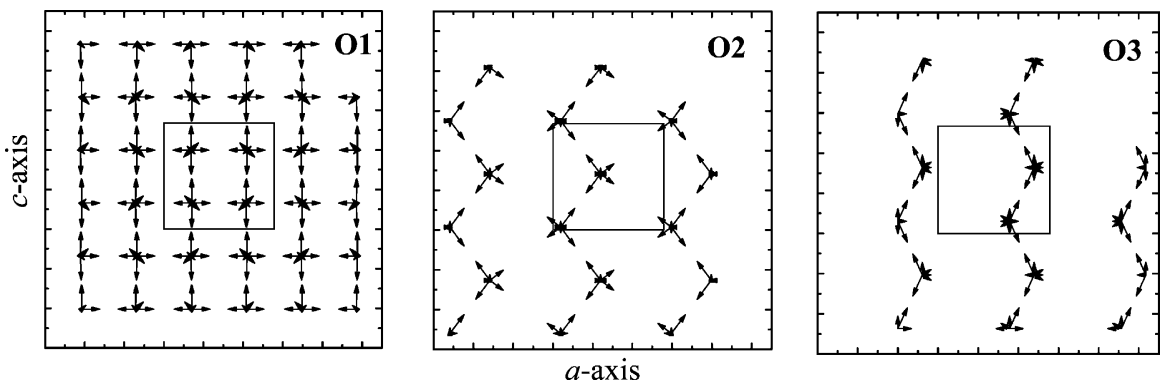

Fig. 7. Maps of the ion jump probability between O1-O1 (left), O2-O2 (center), and O3-O3 (right) sites in the lattice of $\mathrm{CaAl}_{0.5} \mathrm{Fe}_{0.5} \mathrm{O}_{2.5+\delta}$ (see text). Rectangles show unit cell cross-section perpendicular to $b$ axis. Length of each vector is proportional to the ion-migration channel size.

mobility of oxygen ions, as observed for the garnet structure [22]. Therefore, even the transport of extra oxygen ions in the tetrahedral layers, where the concentration of intrinsic vacancies is very high, may be hampered due to the structural reasons. The essentially one-dimensional character of the ionic conduction seems to be responsible for the fact that the ionic conductivity of $\mathrm{CaAl}_{0.5} \mathrm{Fe}_{0.5} \mathrm{O}_{2.5+\delta}$ (Fig. 6) is lower than that of $\mathrm{Sr}_{4} \mathrm{Fe}_{6} \mathrm{O}_{13+\delta}$, where the concentration of ionic charge carriers in air is also low, but the transport is two-dimensional [14]. Note that the ideal perovskite structure presents a threedimensional network of linear diffusion pathways. As a result, the ionic conductivity of perovskite-type phases, such as $\mathrm{La}_{0.8} \mathrm{Sr}_{0.2} \mathrm{Fe}_{0.8} \mathrm{Co}_{0.2} \mathrm{O}_{3-\delta}$ or $\mathrm{La}_{0.7} \mathrm{Sr}_{0.3} \mathrm{Fe}_{0.8} \mathrm{Ga}_{0.2} \mathrm{O}_{3-\delta}$, is 20-500 times higher with respect to $\mathrm{CaAl}_{0.5} \mathrm{Fe}_{0.5} \mathrm{O}_{2.5+\delta}$ (Fig. 6).

\section{Conclusions}

Dense single-phase ceramics of brownmillerite $\mathrm{CaAl}_{0.5} \mathrm{Fe}_{0.5} \mathrm{O}_{2.5+\delta}$ were prepared using the GNP technique. At low temperatures, this phase is oxygen hyperstoichiometric in air. Heating up to 700$800 \mathrm{~K}$ leads to oxygen losses, which are accompanied with an increase in the activation energy for total conductivity, drastic expansion and, presumably, partial disordering of the brownmillerite lattice. The average TECs in air are $16.7 \times 10^{-6} \mathrm{~K}^{-1}$ at $370-850 \mathrm{~K}$ and $12.6 \times 10^{-6} \mathrm{~K}^{-1}$ at $930-1300 \mathrm{~K}$. Oxygen 
permeability of $\mathrm{CaAl}_{0.5} \mathrm{Fe}_{0.5} \mathrm{O}_{2.5+\delta}$ membranes at $1123-1273 \mathrm{~K}$ is limited by the bulk ionic conduction; the effect of surface exchange kinetics was found negligible. The ion transference numbers in air vary from $2 \times 10^{-3}$ to $5 \times 10^{-3}$ and increase with temperature, since the activation energy for oxygen ionic transport, $170 \mathrm{~kJ} / \mathrm{mol}$, is higher than that for electronic conductivity $(93 \mathrm{~kJ} / \mathrm{mol})$. The analysis of structural parameters showed that the ionic conduction in $\mathrm{CaAl}_{0.5} \mathrm{Fe}_{0.5} \mathrm{O}_{2.5+\delta}$ is essentially onedimensional, along the $c$ axis of the brownmillerite lattice. The largest ion-migration channels exist in the perovskite-type layers formed by iron-oxygen octahedra.

\section{Acknowledgements}

This work was supported by the NATO Science for Peace Program (Project 978002), the FCT, Portugal (POCTI Program and Project BD/6595/2001), the INTAS (Project 00276), and the Belarus Ministry of Education.

\section{References}

[1] H.J.M. Bouwmeester, A.J. Burggraaf, in: A.J. Burggraaf, L. Cot (Eds.), Fundamentals of Inorganic Membrane Science and Technology, Elsevier, Amsterdam, 1996, pp. 435-528.

[2] S.P.S. Badwal, F.T. Ciacchi, Adv. Mater. 13 (2001) 993.

[3] J.P.P. Huijsmans, Curr. Opin. Solid State Mater. Sci. 5 (2001) 317.

[4] M. Schwartz, J.H. White, A.F. Sammells, US Patent 6214757 (2001).

[5] T.J. Mazanec, T.L. Cable, J.G. Frye, W.R. Kliewer, US Patent 5591315 (1997).

[6] V.V. Kharton, F.M. Figueiredo, A.V. Kovalevsky, A.P. Viskup, E.N. Naumovich, J.R. Jurado, J.R. Frade, Defect Diffus. Forum 186/187 (2000) 119.

[7] Y. Tsuruta, T. Todaka, H. Nisiguchi, T. Ishihara, Y. Takita, Electrochem. Solid State Lett. 4 (2001) E13.

[8] V.V. Kharton, A.A. Yaremchenko, A.P. Viskup, M.V. Patrakeev, I.A. Leonidov, V.L. Kozhevnikov, F.M. Figueiredo, A.L. Shaulo, E.N. Naumovich, F.M.B. Marques, J. Electrochem. Soc. 149 (2002) E125.

[9] V.V. Kharton, A.A. Yaremchenko, A.V. Kovalevsky, A.P. Viskup, E.N. Naumovich, P.F. Kerko, J. Membr. Sci. 163 (1999) 307.

[10] M.V. Patrakeev, E.B. Mitberg, A.A. Lakhtin, I.A. Leonidov, V.L. Kozhevnikov, V.V. Kharton, M. Avdeev, F.M.B. Marques, J. Solid State Chem. 167 (2002) 203.

[11] J.-C. Grenier, N. Ea, M. Pouchard, P. Hagenmuller, J. Solid State Chem. 58 (1985) 243.

[12] A.F. Sammells, R.L. Cook, J.H. White, J.J. Osborne, R.C. MacDuff, Solid State Ionics 52 (1992) 111.

[13] V.L. Kozhevnikov, I.A. Leonidov, M.V. Patrakeev, E.B. Mitberg, K.R. Poeppelmeier, J. Solid State Chem. 158 (2000) 320.

[14] V.V. Kharton, A.V. Kovalevsky, A.P. Viskup, J.R. Jurado, F.M. Figueiredo, E.N. Naumovich, J.R. Frade, J. Solid State Chem. 156 (2001) 437.

[15] M.Yu. Avdeev, M.V. Patrakeev, V.V. Kharton, J.R. Frade, J. Solid State Electrochem. 6 (2002) 217.

[16] V.V. Kharton, A.P. Viskup, E.N. Naumovich, A.A. Tonoyan, O.P. Reut, Mater. Res. Bull. 33 (1998) 1087.

[17] M.W. Murphy, T.R. Armstrong, P.A. Smith, J. Am. Ceram. Soc. 80 (1997) 165.

[18] Y.-J. Yang, T.-L. Wen, H. Tu, D.Q. Wang, J. Yang, Solid State Ionics 135 (2000) 475.

[19] J. Rodriguez-Carvajal, Physica B 192 (1993) 55.

[20] A.A. Colville, S. Geller, Acta Crystallogr. B 27 (1971) 2311.

[21] P. Berastegui, S. Hull, F.J. Garcia-Garcia, S.-G. Eriksson, J. Solid State Chem. 164 (2002) 119.

[22] V.V. Kharton, A.L. Shaula, E.N. Naumovich, N.P. Vyshatko, I.P. Marozau, A.P. Viskup, F.M.B. Marques, J. Electrochem. Soc. (2003) in press.

[23] H. Hayashi, H. Inaba, M. Matsuyama, N.G. Lan, M. Dokiya, H. Tagawa, Solid State Ionics 122 (1999) 1. 